\title{
ANTECEDENTES DE LA REFORMA DE LA CAPACIDAD en el Código Civil Peruano
}

\author{
ENRIQUE VARSI ROSPIGLIOSI* \\ Universidad de Lima, Lima, Perú \\ Valeria Chávez Romero** \\ Pontificia Universidad Católica del Perú, Lima, Perú \\ Recibido: 19/7/2021 Aprobado: 1/8/2021 \\ doi: https://doi.org/10.26439/iusetpraxis2021.n053.5306
}

\begin{abstract}
RESUMEN. El presente artículo presenta un recuento del proceso de adaptación normativa de nuestro ordenamiento jurídico a partir de la Convención Internacional sobre los Derechos de las Personas con Discapacidad, que trajo como resultado la reforma de la capacidad en nuestro Código Civil en el año 2018. La Convención dio paso a un nuevo concepto de capacidad, además de nuevos parámetros de tratamiento, promoviendo el modelo social y una perspectiva más inclusiva en los derechos fundamentales de las personas con discapacidad. Esto tuvo un gran impacto internacional y en nuestra legislación constituye la más grande reforma realizada por una sola norma.
\end{abstract}

PALABRAS CLAVE: discapacidad / capacidad jurídica / capacidad de ejercicio / apoyos / salvaguardias

\footnotetext{
* Doctor en Derecho por la Universidad Nacional Mayor de San Marcos. Profesor principal e investigador en la Universidad de Lima y en la Universidad Nacional Mayor de San Marcos. Investigador RENACYT (P0010485) del CONCYTEC. Responsable del Grupo de Investigación en Derecho Civil del Instituto de Investigación Científica de la Universidad de Lima.

** Estudiante de Derecho de la Pontificia Universidad Católica del Perú. Miembro del Grupo de Investigación en Derecho Civil del Instituto de Investigación Científica de la Universidad de Lima. Asociada ordinaria de la Asociación Civil lus et Veritas.
} 


\section{ANTECEDENTS OF THE CAPACITY REFORM IN THE PERUVIAN CIVIL CODE}

ABSTRACT. This article focuses on an account of the process of normative adaptation of our legal system based on the Convention on the Rights of Persons with Disabilities, which lead to the reform of capacity in our Civil Code in 2018. The Convention brought a new concept of capacity and new parameters of its treatment, promoting the social model and a more inclusive perspective on the fundamental rights of persons with disabilities. This had a significant impact on our legislation; its changes constituted the most significant reform that has been realized by only one norm and completely transformed the legal treatment of capacity in our country.

KEYWORDS: disability / legal capacity / legal agency / support / safeguards 


\section{INTRODUCCIÓN}

La capacidad y su tratamiento jurídico actualmente constituyen un tema pendiente en nuestro medio, siempre lo han sido. Desde sus orígenes normativos, en el Perú se recurrió a la interdicción y la respectiva designación de un curador para que los (erróneamente denominados) incapaces, por interposita persona, pudieran realizar negocios jurídicos válidos. Es posible sostener que aquel sistema era claramente paternalista; la persona con discapacidad era apartada, desintegrada, no considerada e impedida de ejercer plenamente sus derechos. Aquello significó un serio problema en cuanto al respeto del principio de reserva de la dignidad e igualdad de la persona.

La curatela, como típico sistema de sustitución de voluntad, se presentaba como un serio obstáculo para la integración a la vida comunitaria de las personas con discapacidad, además de impedir su realización personal'1. Este constituía un régimen gravoso (León Hilario, 2019, p. 71) al promover la transferencia compulsoria de decisiones a un tercero, aniquilando su voluntad y su preferencia; el resultado de ello equivalía a una verdadera muerte civil (Farias y Rosenvald, 2018, p. 366).

La reforma de la capacidad en el Código Civil, a través del Decreto Legislativo 1384, publicado en el diario oficial El Peruano el 4 de septiembre del 2018, abrió paso a un nuevo tratamiento de la capacidad en materia civil. Tras un largo proceso, nuestro sistema finalmente se adaptó a la Convención Internacional sobre los Derechos de las Personas con Discapacidad del 2007 (Varsi Rospigliosi y Torres Maldonado, 2019, p. 199). Este no fue un proceso sencillo; empezó con la promulgación de la Ley General de la Persona con Discapacidad en el año 2012 y no fue sino hasta seis años después, con la emisión del Decreto Legislativo 1384, cuando se implementaron múltiples modificaciones a nuestro Código Civil que permitieron adoptar un tratamiento más adecuado a esta institución clásica del derecho civil.

Como resultado de esta única norma se realizaron diversas derogaciones, modificaciones e incorporaciones a nuestro Código. A través de este se reconoció que las personas con discapacidad poseen capacidad jurídica de ejercicio. Además, se reemplazó la figura de la curatela por la designación de apoyos y salvaguardias (Bustamante, 2019, p. 2), entre otros cambios significativos. De esta manera, gracias a la reforma, se otorgó a la persona con discapacidad un mayor régimen de control en la autonomía de su voluntad.

1 Resulta curioso destacar que el sistema de custodia legal de los incapaces no surgió con una intención protectora, sino todo lo contrario. Apareció en Inglaterra durante el siglo XIV para asegurar que el rey se adueñara de las propiedades de los idiotas. Es indubitable que, luego de más de cinco siglos, el cuestionamiento y superación de dicha institución resultara por demás imperante. 


\section{LA CONVENCIÓN INTERNACIONAL SOBRE LOS DERECHOS DE LAS PERSONAS CON DISCAPACIDAD}

La Convención Internacional sobre los Derechos de las Personas con Discapacidad $(2007)^{2}$ es el primer tratado de derechos humanos del siglo XXI, como dice Palacios (2015, p. 14). Su promulgación condujo a un cambio de paradigma que tuvo un impacto internacional en las normas civiles que regulaban la institución de la capacidad.

Introduce el modelo social de la discapacidad planteando que esta "no responde a un aspecto inherente de la persona, sino a la interacción entre la deficiencia de la misma y las barreras sociales que impone la sociedad" (Mamani, 2018, párr. 4). En otras palabras, se parte de la idea de que "el problema de la discapacidad deja de explicarse a partir de la 'deficiencia' de la persona, para pasar a hacerlo a partir de las 'deficiencias' de la sociedad, que se traducen en barreras discapacitantes" (Palacios, 2015, p. 14).

Este modelo fue precedido por el modelo de prescindencia y el modelo rehabilitador, en ese orden. El modelo de prescindencia consideraba que el origen de la discapacidad se debía a un motivo religioso, se asumía que la discapacidad era un castigo divino y, por lo tanto, las personas con discapacidad eran separadas de la sociedad (Palacios, 2015, p. 10). La persona en condición de discapacidad era marginada, rechazada y excluida civilmente, ya que se prescindía de ella, no era considerada como sujeto jurídicamente relevante.

Por su parte, el modelo rehabilitador persigue como finalidad "rehabilitar" la discapacidad de la persona; en otros términos, la discapacidad era observada como una enfermedad que debe ser curada. El problema principal surgía porque existen múltiples discapacidades que no son susceptibles de rehabilitación de ningún tipo (Palacios, 2015, p. 12). En el aspecto civil, "la discapacidad es abordada exclusivamente dentro de la legislación de la asistencia y seguridad social, o como parte de ciertas cuestiones del derecho civil relacionadas con la incapacitación y la tutela" (Palacios, 2015, p. 13).

Es claro que los modelos anteriores recaían en un tratamiento jurídico discriminatorio hacia las personas con discapacidad, limitando y negando un adecuado ejercicio de sus derechos fundamentales y civiles. A diferencia de ellos, el modelo social brinda un nuevo entendimiento del tratamiento jurídico a la persona con discapacidad. Bajo el modelo social, la discapacidad de una persona se entiende como la dificultad en su

2 Aprobada por la Asamblea General de las Naciones Unidas en su sexagésimo primer periodo de sesiones, mediante la Resolución NRES/61/106, del 13 de diciembre del 2006; aprobada por el Congreso de la República mediante la Resolución Legislativa 29127, del 30 de octubre del 2007, publicada en el diario oficial El Peruano el 1 de noviembre del 2007; y ratificada por el presidente de la República, según el Decreto Supremo 073-2007-RE, del 30 de diciembre del 2007, publicado en el diario oficial El Peruano el 31 de diciembre del 2007. 
interactuar social por causas de la sociedad, al no brindarle mecanismos facilitadores de su libre desenvolvimiento.

En este sentido, es la sociedad la que ha generado obstáculos a la integración de las personas con discapacidad por diversos medios, especialmente por el estigma y la discriminación que dificultan dicha integración, y a ello se han sumado los medios legales (Ramírez Niño de Guzmán, 2018, p. 108). Son los impedimentos que encuentran los que impiden su desarrollo, imposibilitando el pleno ejercicio de sus derechos y su interacción social. Así "la discapacidad no es una condición estática que radique en la persona, sino un constructo social móvil que surge de la interacción entre la deficiencia de la persona y las barreras que establece la sociedad" (Bregaglio y Constantino, 2020, p. 35).

La Convención tiene como máximo propósito promover, proteger y asegurar el goce pleno y en condiciones de igualdad de los derechos humanos y libertades fundamentales de todas las personas con discapacidad, así como fomentar el respeto de su dignidad inherente. El nuevo enfoque de la capacidad en la normativa nacional se adecúa a las directrices de las Naciones Unidas en pro de la autonomía y la plena capacidad jurídica de las personas con discapacidad, concordando la legislación nacional con la Convención. Busca, además, garantizar libertades fundamentales de todas las personas con discapacidad y promover el respeto de su dignidad.

Plantea un cuestionamiento al término incapacidad, a la institución de la interdicción y la curatela, partiendo de la premisa de que estas instituciones sustituyen la voluntad, restringen la libertad y la autodeterminación, apartando al sujeto de sus decisiones. Lo que sugiere la Convención no es la sustitución, sino, por el contrario, la inclusión de la persona con discapacidad a través de ajustes razonables o apoyos. Ello en virtud de que puedan expresar su fiel voluntad, se viabilice su actuar y se permita el libre ejercicio de su libertad.

Se deja de lado el tratamiento paternalista a las personas con discapacidad y estas pasan a ser parte de un régimen de igualdad jurídica, produciéndose un reconocimiento de su autodeterminación. En este marco, "se pasa del modelo tradicional de la sustitución, mediante la representación, al modelo de apoyo o asistencia al discapacitado en la toma de decisiones" (Torres Vásquez, 2018, p. 90). El régimen de sustitución de la voluntad de las personas incapaces (excluyente) es reemplazado por un modelo social (incluyente) o de asistencia a través de los denominados apoyos y salvaguardias.

Nos encontramos, naturalmente, ante un modelo inclusivo, democrático, acorde al respeto a los derechos humanos de todos los ciudadanos. Especialmente en cuanto a su dignidad e igualdad ante la ley, tomando en cuenta que se sustituye el término incapacidad por el de discapacidad. Se implementan los apoyos y las salvaguardias, y solo mantiene la interdicción y la curatela para casos específicos (discapacidad percibida) 
señalados en los incisos 4 al 8 del artículo 44 (artículo 564) como sujetos con capacidad restringida (ya no incapaces relativos), en la medida, como dice León Hilario (2019, p. 73), que no hayan designado un apoyo con anterioridad.

Es un modelo social que toma como base la igualdad y dignidad de las personas con discapacidad dentro de un sistema democrático:

\begin{tabular}{cc}
\hline Inclusión & Social \\
\hline Igualdad & Dignidad \\
Capacidad & \\
Estado de derecho \\
\hline
\end{tabular}

Este modelo social responde a un reconocimiento a la autonomía de la que goza la persona, entendiéndola en su dignidad como pilar de su desarrollo social, con los medios psicológicos para decidir respecto a su propia vida y el reconocimiento de la libertad que le permita tomar sus propias decisiones. Para Bariffi (2020b), el modelo de toma de decisiones con apoyos podría sintetizarse del siguiente modo:

El reconocimiento y la garantía del derecho:

- Al ejercicio de la capacidad jurídica

- A recibir apoyos para hacer efectivo el ejercicio de la capacidad jurídica

La reforma efectuada en el Código logra unir los cabos sueltos en la legislación peruana en torno al artículo 12 de la Convención que regula la autonomía y capacidad jurídica de las personas con discapacidad, el cual consagra:

Artículo 12.- Igual reconocimiento como persona ante la ley

1. Los Estados Partes reafirman que las personas con discapacidad tienen derecho en todas partes al reconocimiento de su personalidad jurídica.

2. Los Estados Partes reconocerán que las personas con discapacidad tienen capacidad jurídica en igualdad de condiciones con las demás en todos los aspectos de la vida.

3. Los Estados Partes adoptarán las medidas pertinentes para proporcionar acceso a las personas con discapacidad al apoyo que puedan necesitar en el ejercicio de su capacidad jurídica.

4. Los Estados Partes asegurarán que en todas las medidas relativas al ejercicio de la capacidad jurídica se proporcionen salvaguardias adecuadas y efectivas para impedir los abusos, de conformidad con el derecho internacional en materia de derechos humanos. Esas salvaguardias asegurarán que las medidas relativas al ejercicio de la capacidad jurídica respeten los derechos, la voluntad y las preferencias de la persona, que no haya conflicto de intereses ni influencia indebida, que sean proporcionales y adaptadas a las circunstancias de la persona, 
que se apliquen en el plazo más corto posible y que estén sujetas a exámenes periódicos por parte de una autoridad o un órgano judicial competente, independiente e imparcial. Las salvaguardias serán proporcionales al grado en que dichas medidas afecten a los derechos e intereses de las personas.

5. Sin perjuicio de lo dispuesto en el presente artículo, los Estados Partes tomarán todas las medidas que sean pertinentes y efectivas para garantizar el derecho de las personas con discapacidad, en igualdad de condiciones con las demás, a ser propietarias y heredar bienes, controlar sus propios asuntos económicos y tener acceso en igualdad de condiciones a préstamos bancarios, hipotecas y otras modalidades de crédito financiero, y velarán por que las personas con discapacidad no sean privadas de sus bienes de manera arbitraria.

La tabla 1 presenta un esquema de este artículo.

Tabla 1

Esquema del artículo 12 de la Convención, sobre el igual reconocimiento ante la ley de las personas con discapacidad

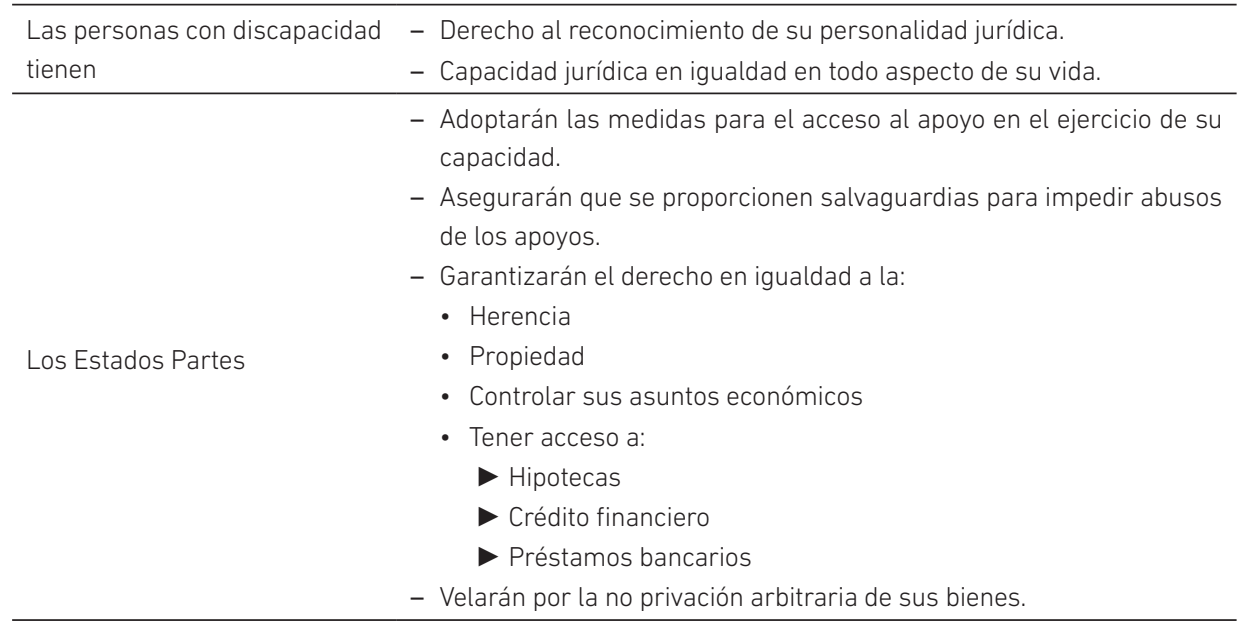

Lo resumiríamos aún más en tres puntos:

- Igualdad en la personalidad jurídica (capacidad de goce: titularidad) y en la capacidad jurídica (capacidad de ejercicio: aptitud)

- Apoyos y salvaguardias

- Derecho a la propiedad (herencia y contratar)

El artículo 12 resalta entre los demás por el desafío que implica su aplicación efectiva en la práctica, tal y como sostiene Bariffi (2020a): "El artículo 12 constituye muy probablemente el mayor desafío que presenta la CDPD, es decir, garantizar la igualdad en el ámbito de la capacidad jurídica" (p. 14). Con este artículo se reafirma que todas las 
personas con discapacidad tienen plena capacidad jurídica. El derecho, como reconocimiento de la persona ante la ley, exige que la capacidad jurídica sea un atributo esencial, inherente a todas a las personas en razón de su humanidad, y ello significa el reconocimiento a las personas con discapacidad en igualdad de condiciones con las demás. Como dice Bariffi (2020a), la Convención "recoge un estándar universal que garantiza a todas las personas con discapacidad su derecho de decidir sobre el ejercicio de sus derechos humanos" (p. 3).

Se puede sintetizar en la siguiente fórmula:

$\begin{array}{cc}\text { Apoyos + salvaguardias } & \begin{array}{c}\text { Toma de } \\ \text { Capacidad }\end{array}\end{array}$

Por todo lo anteriormente mencionado, es posible sostener que los apoyos y salvaguardias son el núcleo duro del artículo 12 de la Convención.

\section{DERECHO COMPARADO}

Como resultado de la Convención, los Estados partes adscritos se encontraron comprometidos a adaptar su normativa civil de acuerdo con los nuevos parámetros establecidos en esta. La línea moderna que conlleva el modelo social busca eliminar la marginalización, tendiendo a una integración social a través de medidas de protección menos invasivas (Corral Talciani, 2018, p. 397). "Se pasa de una mirada médico/caritativa a una perspectiva de derechos humanos"; se busca que la persona con discapacidad participe en las decisiones que afectan su vida, respetándose y garantizándose sus derechos (Simon Campaña, 2017, p. 308).

El sistema civil comparado ha venido reaccionado sobre las nuevas perspectivas de la capacidad (Espinoza Espinoza, 2019, pp. 1240 y ss.) con el paso de los años. En el continente europeo, estas actualizaciones se presentaron incluso mucho antes de la Convención del 2007. Así tenemos en Francia una modificación por L. 68-5/68, en la cual se incorpora la figura del sauvegarde de justice. En España, a través de la L. 13/1983, se reforma el viejo Código de 1879, en el que se indicaba la existencia de causas específicas para el sometimiento a tutela o curatela de las personas incapaces por enfermedades permanentes, físicas o psíquicas, que les impidiesen gobernarse. En Austria, por la L. 136/83, se realizaron cambios en referencia a la representación de las personas disminuidas, así como por la L. 140/79, que sustituye la interdicción e inhabilitación por la figura de la Sachwalterschaft, una forma de designar un administrador. En Alemania, a través de la Ley de Cuidado, emitida el 12 de septiembre de 1990, se reforma la tutela (Betreuungsgesetz [BtG]), vigente desde 1992, dejando sin efecto la interdicción y la curatela. Por último, en Italia, por la L. 6 del 9 de enero del 2004, se sienta como base 
el proyecto Cendon, que acoge la figura de la administración de sostenimiento, amministrazione di sostegno.

En Latinoamérica, respecto a los más actuales tratamientos de la capacidad en cuanto a derechos humanos, muchos países también sumaron nuevos tratamientos en sus ordenamientos civiles. Argentina fue el primer país que adecuó su Código Civil a los criterios de la Convención incorporando la figura del apoyo; empero, no se eliminó el régimen de la curatela (Frecha, 2019, p. 93). Asimismo, limitó la posibilidad de imponer la interdicción a personas con discapacidad mental; sin embargo, no descartó esta figura (Bregaglio y Constantino, 2020). En Brasil, a través de la Ley núm. 13.146/15, se modificó el estatuto de las personas con discapacidad en el año 2008 (Nelson et al., 2019, p. 98). Colombia, mediante la Ley 1306 aprobada en el año 2009, incorporó a su ordenamiento una mayor protección a las personas con discapacidad mental (Saavedra y Sánchez, 2015, p. 27). Sin embargo, esta ley no era perfecta, ya que se establecieron dos categorías: la discapacidad mental absoluta y la discapacidad mental relativa. Como resultado de esta primera categoría, correspondía llevar a cabo una declaratoria de interdicción; y, en el caso de ser declarada la discapacidad mental relativa, como consecuencia jurídica se declaraba la inhabilidad. Posteriormente, en el 2019, se emitió la Ley 1996 que modificó la Ley 1306, en la cual se reconoció que las personas con discapacidad cuentan con capacidad jurídica, independientemente de si tienen o no apoyos. Asimismo, se erradicó la diferenciación entre discapacidad mental absoluta y discapacidad mental relativa, así como sus anteriores consecuencias jurídicas (Orrego, 2019, p. 10).

En Chile también se realizaron distintas modificaciones en virtud de la Convención a través de leyes como la Ley 19.954, por la cual se modificó radicalmente el proceso de interdicción de las personas en situación de discapacidad mental (anteriormente realizada a través de proceso contencioso) y la respectiva designación de su curador de bienes (López, 2015, pp. 43-44). Sin embargo, estas modificaciones fueron bastante comentadas en la doctrina debido a que fueron percibidas como un cambio "simbólico". Ello en virtud de que, a pesar de estos cambios, se percibía una continuación de la primacía del modelo médico-rehabilitador por sobre el modelo social planteado en la Convención (López, 2015, pp. 45-47).

\section{LA REFORMA EN EL PERÚ}

Nuestro ordenamiento legal no solo se rige por normas internas, sino que responde también a tratados y convenios internacionales. Debido a que estos versan sobre derechos humanos, tienen jerarquía y rango constitucional, por lo que el Estado, en ese escenario, debe reestructurar su orden interno. Es por ello que los sistemas infraconstitucionales deben estar alineados al nuevo espíritu inclusivo constitucional dedicado a la persona con discapacidad (Farias y Rosenvald, 2018, p. 363). 
Existe un conjunto de instrumentos internacionales de los que nuestro ordenamiento es tributario, como la Declaración Universal de los Derechos Humanos (1948), la Convención sobre los Derechos del Niño (1989), la Convención Americana sobre los Derechos Humanos (1969) y la Convención Internacional sobre los Derechos de las Personas con Discapacidad (2007).

Esta última, la Convención Internacional sobre los Derechos de las Personas con Discapacidad, como se explicó anteriormente, introdujo nuevos parámetros en cuanto al tratamiento de la capacidad desde los derechos humanos. A través de ella, se pasó a promover y asegurar que las personas con discapacidad pudieran ejercer el goce pleno de todos sus derechos humanos, lo que implica el íntegro respeto de su dignidad como valor fundante de su existencia. En virtud de ello, se acogió el modelo social, el cual

[...] se encuentra íntimamente relacionado con la asunción de ciertos valores intrínsecos a los derechos humanos y aspira a potenciar el respeto por la dignidad humana, la igualdad y la libertad personal, propiciando la inclusión social y asentándose sobre la base de determinados principios: vida independiente, no discriminación, accesibilidad universal, normalización del entorno, participación, entre otros. (Palacios, 2015, p. 14)

Sin embargo, nuestro Código Civil no se adaptó a los nuevos alcances de los derechos de las personas con discapacidad establecidos en la Convención y ratificados en el 2008 sino hasta el año 2018. La reforma legislativa del Código Civil no fue apresurada ni improvisada; constituyó un largo proceso, incluso podría sostenerse que tomó más años de la cuenta. La reforma fue producto de un extenso proceso de adecuación normativa, un proceso evolutivo que nace de la teoría de los derechos humanos (anexo 4 de la Convención). En efecto, Bariffi (2020a) nos dice:

[...] los derechos humanos empiezan a cuestionar el concepto del ejercicio de los derechos al considerar que el ejercicio es precisamente parte intrínseca de los mismos. Los derechos humanos tienen que garantizar igualdad en el ejercicio de los derechos, lo que significa necesariamente irrumpir en el sistema clásico del derecho civil que viene en nuestros ordenamientos derivados del derecho romano, y más directamente del Código Napoleónico. (p. 11)

En este marco, se produjo una gran reforma en el Código Civil principalmente a partir del Decreto Legislativo 1384, publicado el 4 de septiembre del 2018, y su reglamento (Decreto Supremo 016-2019-MIMP, publicado el 25 de agosto del 2019), que reconoce y regula la capacidad jurídica de las personas con discapacidad en igualdad de condiciones. Asimismo, el Decreto Legislativo 1377, publicado el 24 de agosto del 2018, fortalece la protección integral de los niños y adolescentes. En este se hace referencia a los supuestos en los cuales los menores de edad adquirirán capacidad jurídica, así como a los escenarios en los que podrán ejercer esta. Por su parte, el Decreto Legislativo 1417, publicado el 13 de septiembre del 2018, promueve la inclusión de las personas 
con discapacidad. En este se establece principalmente lo relativo a la designación de ajustes razonables, de apoyos y salvaguardias, así como las respectivas adaptaciones que tendrán que seguir los empleadores de personas con discapacidad.

Este nuevo marco normativo comprometió a la comunidad jurídica a reconsiderar “la posición de las personas que tradicionalmente, por el fuerte e incuestionado arraigo de una óptica paternalista, han sido excluidas o limitadas, hasta niveles discriminatorios, para su libre desenvolvimiento en el plano del derecho" (León Hilario, 2014, p. 92). Es decir, a repensar el tratamiento de la capacidad jurídica en virtud de una mayor inclusión hacia las personas con discapacidad, con ánimo de evitar instituciones restrictivas que perjudiquen sus derechos fundamentales individuales.

\section{Proceso de adaptación normativa previo a la reforma}

Como se mencionó, la reforma del tratamiento de la capacidad en el Código Civil peruano fue resultado de un largo proceso de adaptación normativa. Este proceso no inició con los decretos que modificaron el Código, sino que previamente fueron realizándose cambios en otras fuentes de nuestra legislación.

\section{Ley General de la Persona con Discapacidad}

Después de aproximadamente cuatro años de la ratificación por el Perú de la Convención, se dictó la Ley 29973, publicada el 24 de diciembre del $2012^{3}$, conocida también como Ley General de la Persona con Discapacidad. Esta introduce cambios sustanciales y transversales al ordenamiento jurídico peruano.

Esta ley tiene como objetivo promover, proteger y permitir la realización de los derechos de las personas con discapacidad, incentivando su desarrollo e inclusión social plena y efectiva. La norma parte del respeto a la dignidad, la autonomía y libertad como valores inherentes de la persona, así como del derecho a la igualdad y no discriminación, el respeto por la diferencia y la aceptación de las personas con discapacidad como parte de la diversidad y condición humana (artículo 4). Reconoce el rol de la familia, como institución social, en la inclusión y participación efectiva en la vida social de este tipo de personas, prestándole orientación y capacitación integral, así como un fácil acceso a servicios y programas de asistencia social (artículo 5).

La Ley General de la Persona con Discapacidad está en consonancia con el artículo 7 de la Constitución, que considera que la persona incapacitada para velar por sí misma a causa de una deficiencia física o mental tiene derecho al respeto de su dignidad y a un

3 Esta ley cuenta con un reglamento, Decreto Supremo 002-2014-MIMP, publicado el 8 de abril del 2014. 
régimen legal de protección, atención, readaptación y seguridad. A manera de énfasis legal, se reconoce a la persona con discapacidad, especialmente, el derecho a la vida, a la integridad (moral, física y mental) y al consentimiento informado en las investigaciones médicas o científicas en que participe (artículo 7); a la capacidad jurídica, como atributo, estableciendo que "el Código Civil regula los sistemas de apoyo y los ajustes razonables que requieran para la toma de decisiones" (9.1., artículo 9). En el aspecto patrimonial, tiene derecho a la propiedad, a la herencia, a contratar, a dar en garantía, a préstamos bancarios y a créditos financieros y (de forma desarticulada en este esquema de derechos económicos) se le reconoce el derecho a contraer matrimonio y decidir libremente su sexualidad y fertilidad (9.2., artículo 9) (Varsi Rospigliosi, 2013, p. 4). Con esta ley, como dice Campos García (2013), es intención del legislador "romper con el inicuo binomio discapacidad-incapacidad" (p. 6).

La segunda disposición complementaria final de la Ley 29973, Ley General de la Persona con Discapacidad, que se promulgó el 24 de diciembre del 2012, fue modificada por la Ley 30121 el 5 de diciembre del 2013, en la cual finalmente se promulgó la creación de la Comisión Especial Revisora del Código Civil (CEDIS):

Constitúyese una comisión especial encargada de revisar el Código Civil en lo referido al ejercicio de la capacidad jurídica de la persona con discapacidad y formular, en un plazo no mayor a seis meses, contado a partir de la entrada en vigencia de la presente Ley, un anteproyecto de ley de reforma del Código Civil que se ajuste a lo establecido en la presente Ley y en la Convención sobre los Derechos de las Personas con Discapacidad.

La CEDIS estuvo conformada por siete representaciones institucionales con un total de diez miembros:

1. Dos congresistas de la República, uno de los cuales la preside

2. Un representante del Consejo Nacional para la Integración de la Persona con Discapacidad (CONADIS)

3. Un representante del Poder Judicial

4. Un representante de las universidades que tengan Facultades de Derecho, el cual es designado por la Asamblea Nacional de Rectores

5. Un representante de la Defensoría del Pueblo

6. Un representante del Registro Nacional de Identificación y Estado Civil

7. Tres representantes de las organizaciones de personas con discapacidad

Sus integrantes se presentan en la tabla 2. 
Tabla 2

Representantes que integraron la CEDIS

\begin{tabular}{ll}
\hline Institución & Representante \\
\hline Congresistas de la República & Jhon Reynaga Soto \\
& Presidente \\
& Rosa Delsa Mavila León \\
& Vicepresidente \\
Representante de las universidades & Leysser Luggi León Hilario \\
PUCP-ANR & Secretario \\
Poder Judicial & Ulises Yaya Zumaeta \\
Defensoría del Pueblo & Malena Patricia Pineda Ángeles \\
RENIEC & Carlo Magno Salcedo \\
CONADIS & Julio Wilfredo Guzmán Jara \\
Sociedad Peruana de Síndrome de Down & Liliana Peñaherrera Sánchez \\
Sociedad y Discapacidad (SODIS) & Alberto Vásquez Encalada \\
Centro de Promoción de la Salud Mental & Elena Chávez Ramírez \\
\hline
\end{tabular}

Elaboración propia

Sus miembros alternos fueron:

- Elizabeth Calle Ato (CONADIS)

- Lilia Teresa Aguilar Nonajulca (Poder Judicial)

- Renata Anahí Bregaglio Lazarte (ANR-PUCP)

- María Isabel León Esteban (Defensoría del Pueblo)

- Carlos A. Fernández de Córdova Macera (RENIEC)

- Costanza Borea Rieckhof (Sociedad Peruana de Síndrome de Down)

- Gladys Hermelinda Fernández Chira (Sociedad y Discapacidad [SODIS])

- Julio Martín Meza Díaz (Centro de Promoción de la Salud Mental Álamo)

Los proyectos de ley

La CEDIS elaboró un anteproyecto de ley que presentó al Congreso, pero este fue archivado. 
Dos años después, fue retomado como una iniciativa legislativa multipartidaria cuyo trabajo terminó en el Proyecto de Ley 872/2016-CR del 13 de enero del $2016^{4}$ que es el antecedente 0 , como dicen algunos, la madre del Decreto Legislativo 1384.

\section{Constitución Política y la interpretación del Tribunal Constitucional}

La fuente normativa de máxima jerarquía en nuestro sistema jurídico es la Constitución. En el año 2008, tras ratificarse la Convención, se encontraba en vigencia la Carta Magna del año 1993. Actualmente esta sigue en vigencia.

En este marco, el artículo 7 de la Constitución precisa: "La persona incapacitada para velar por sí misma a causa de una deficiencia física o mental tiene derecho al respeto de su dignidad y a un régimen legal de protección, atención, readaptación y seguridad". No es un artículo muy adecuado en la línea del mandato de la Convención. La terminología es errónea y sigue la tendencia de las deficiencias (física o mental), debido a los sesgos propios de la época en la que fue publicada (1993).

Sin embargo, el Tribunal Constitucional, máximo intérprete de la Constitución, sí se ha pronunciado a través de diferentes sentencias acerca del nuevo tratamiento que se debe dar a las personas con discapacidad, a la luz de la Convención. Sobre el particular, es importante la atención y análisis que realiza Sokolich Alva (2015) sobre este artículo constitucional.

Acerca de esta disposición constitucional, el Tribunal Constitucional en la sentencia recaída en el Expediente 02480-2008-PA/TC (2008) ha señalado:

[...] la Constitución reconoce a las personas con discapacidad mental como sujetos de especial protección debido a las condiciones de vulnerabilidad manifiesta por su condición psíquica y emocional, razón por la cual les concede una protección reforzada para que puedan ejercer los derechos que otras personas, en condiciones normales, ejercen con autodeterminación. (Fundamento jurídico 13)

En esta línea, además, el Tribunal Constitucional en la sentencia recaída en el Expediente 02313-HC/TC (2009) ha indicado:

La discapacidad mental no es sinónimo, prima facie, de incapacidad para tomar decisiones. Si bien las personas que adolecen de enfermedades mentales suelen

4 "Proyecto de Ley que modifica el Código Civil, el Código Procesal Civil y la Ley de Notariado en lo referido al ejercicio de la capacidad jurídica de las personas con discapacidad", presentado al Congreso de la República del Perú el 12 de enero del 2017, buscando adecuar el Código Civil, el Código Procesal Civil, la Ley de Notariado y el Código de Niños y Adolescentes al modelo social de discapacidad, el respeto de derechos humanos y la Convención sobre los Derechos de las Personas con Discapacidad. Este proyecto toma como referencia el Proyecto de Ley 4601/2014-CR del 16 de junio del 2015. 
tener dificultad para decidir o comunicar tales decisiones, estas deben ser tomadas en cuenta, puesto que ello es una manifestación de su autodeterminación, y en primera instancia de su dignidad. Ahora bien, el que las decisiones de las personas con discapacidad mental tengan que ser tomadas en cuenta no implica la desaparición o la caducidad de la figura de la curatela. De acuerdo al artículo 576 del Código Civil, el curador protege al incapaz, procurando su restablecimiento y lo representa y asiste en sus negocios, según el grado de la incapacidad. Esto que no es más que una concretización del principio de respeto de la dignidad del ser humano implica que el curador no debe prescindir de la voluntad del interdictado, sino protegerle en todos aquellos aspectos en donde este no puede valorar adecuadamente la toma de decisiones. (Fundamento jurídico 6)

Además, en la sentencia recaída en el Expediente 02437-2013-PA/TC (2014) ha considerado:

[...] cualquier medida que se tome en esta materia se orienta a remover los obstáculos que impiden que las personas con discapacidad gocen de sus derechos de manera plena y puedan ejercerlos, en especial, aquellos que imposibilitan el acceso a ciertos entornos físicos, sin afectarse en ningún caso su autonomía, libertad e independencia. Ha de tratarse, pues, de medidas que fomenten el desarrollo autónomo de las personas con discapacidad en espacios físicos adecuados. (Fundamento jurídico 15)

Asimismo, en su sentencia recaída en el Expediente 01153-2013-PA/TC (2014), el Tribunal Constitucional ha indicado el nuevo enfoque que debe ser tomado en cuenta en torno a la "discapacidad":

[...] este tribunal no puede dejar de hacer notar que la denominada "discapacidad", en realidad, es el no acondicionamiento a un entorno que es hostil para este colectivo. En ese sentido, el nuevo enfoque de la discapacidad lo que resalta es que las alegadas limitaciones o dificultades no emanan de la persona misma, sino de una sociedad que no ha realizado determinados ajustes para garantizar que este colectivo pueda gozar, en condiciones de igualdad, del plexo de derechos y principios que nuestro ordenamiento resguarda. (Fundamento jurídico 6)

En cuanto al tratamiento de la capacidad jurídica en el caso de las personas con discapacidad mental, el Tribunal Constitucional ha acogido el modelo social como el modelo regulador de las personas con discapacidad en nuestro país años antes de la reforma. Aquello es contemplado en la sentencia recaída en el Expediente 02313-2009$\mathrm{PHC} / \mathrm{TC}$ :

[...] en dicha perspectiva, la jurisprudencia de este Tribunal tampoco ha sido ajena a este cambio de paradigma. Por ejemplo, ya desde el fundamento 4 de la sentencia recaída en el Expediente 02313-2009-PHC/TC, se puede vislumbrar como este Tribunal, al señalar que no es posible equiparar la situación de discapacidad mental de una persona con la falta o inexistencia de voluntad, ha ido decantándose por 
impregnar la perspectiva del modelo social en la comprensión de los alcances de los derechos de las personas con discapacidad [...]. En consecuencia, este Tribunal considera que, en el estado actual de las cosas, los derechos y las libertades de las personas con discapacidad deben interpretarse bajo el esquema que propone el modelo social que, como se dejó evidenciado supra, encuentra respaldo constitucional. Solo así, desplazando la "incapacidad" hacia el entorno, podrán combatirse las desigualdades que históricamente han aquejado a este importante sector de la población. (STC 00194-2014-PHC/TC, 2019, fundamento jurídico 15)

Finalmente, el Tribunal Constitucional también destacó en la precitada sentencia la importancia del reconocimiento de las personas con discapacidad mental como sujetos de especial protección constitucional. En este sentido, mencionó lo siguiente:

[...] se ha señalado que si bien el derecho a la salud mental está compuesto por los mismos elementos del derecho a la salud en general, el primero tiene la particularidad de que sus titulares constituyen un sector de la población altamente vulnerable, que requiere de una visión de sus derechos fundamentales desde una óptica que no solo entraña categorías jurídicas, sino también médicas, antropológicas, sociológicas, entre otros aspectos, que han sido considerados por los estándares internacionales de protección de los derechos humanos. (STC $00194-$ 2014-PHC/TC, 2019, fundamento jurídico 35)

Los fragmentos de sentencias citados reflejan que en la jurisprudencia se adoptó lo establecido por la Convención incluso antes que la normativa civil. El Tribunal Constitucional ha ido desarrollando el nuevo enfoque de la capacidad, así como otros conceptos, a través de sus sentencias muchos años antes de una regulación adecuada en materia civil. Este se debe a que, en el día a día, la regulación anterior de la capacidad jurídica para las personas con discapacidad representaba verdaderas restricciones a los derechos fundamentales de estas. En este sentido, el Tribunal Constitucional tuvo que adaptarse lo antes posible a lo acordado en la Convención, en aras del cumplimiento de esta nueva regulación internacional.

Cabe recalcar que, como ya se indicó anteriormente, todos los Estados partes adscritos a la Convención tenían la obligación de adaptar su contenido a su legislación lo más pronto posible. El Tribunal Constitucional, consciente de este hecho, adaptó sus fallos a los estándares de la Convención Internacional sobre los Derechos de las Personas con Discapacidad.

\section{La reforma en el Código Civil}

En septiembre del 2018, el Código Civil fue modificado por el Decreto Legislativo 1384, “Decreto Legislativo que reconoce y regula la capacidad jurídica de las personas con discapacidad en igualdad de condiciones", publicado el 4 de septiembre del 2018. Esta fue una sorpresa para gran parte de los civilistas, incluso para los miembros del Grupo de 
Trabajo que se encargaba de revisar y proponer mejoras respecto al Decreto Legislativo 295. Código Civil ${ }^{5}$, que en esos momentos estaba llevando a cabo su labor.

Lo cierto es que luego de casi seis años de la publicación de la Ley 29973, en la línea de la Convención y de los principios constitucionales, el Poder Ejecutivo, en mérito de las facultades conferidas, dicta el Decreto Legislativo $1384^{6}$ que reconoce y regula la capacidad jurídica de las personas con discapacidad en igualdad de condiciones, promueve su inclusión en las relaciones sociales, garantizando el ejercicio de sus derechos y su capacidad jurídica (exequibilidad de la persona con discapacidad) adecuando el Código al sistema social de la discapacidad.

Precisa con atención Mejía Rosasco (2019, p. 51) que este decreto legislativo no tuvo vacatio legis, sino que se aplicó de manera inmediata. Además, se indicó en la primera disposición complementaria final la exigencia de una reglamentación sobre ajustes razonables, apoyos y salvaguardias, la cual fue encargada al Ministerio de la Mujer y Poblaciones Vulnerables, en coordinación con el Ministerio de Justicia y Derechos Humanos, dándoles un plazo no mayor de ciento ochenta días calendario para ello, contados a partir del día siguiente de la publicación del decreto legislativo.

Con la entrada en vigencia del Decreto Legislativo 1384, hemos virado de un régimen de exclusión a uno de inclusión, democratizando las relaciones sociales y las jurídicas, e integrando a los sujetos independientemente de su discapacidad. No se pretende sustituir la voluntad (Roca Mendoza, 2015, p. 123), sino mantener y, además, integrar a las personas con discapacidad, facilitándoles la vida de relación.

Mientras el sistema tradicional tendía a un modelo de sustitución en la toma de decisiones, como lo es la interdicción y curatela, basado en el paradigma del representante legal-curador (Campos García, 2018, p. 80), el vigente está basado en la igualdad y en la dignidad intrínseca de las personas, y aboga por un modelo social de asistencia a través de apoyo en la toma de decisiones. En consecuencia, la presunción de la capacidad jurídica de todas las personas con discapacidad es un aspecto medular en la reforma del Código, lo que significa que la discapacidad no debe ser motivo de restricción o limitación de la capacidad jurídica: ello es discriminatorio.

5 Resolución Ministerial 0300-2016-JUS, publicada el 18 de octubre del 2016.

6 Por la Ley 30823 se delegó al Poder Ejecutivo "facultad para legislar en materia de gestión económica y competitividad, de integridad y lucha contra la corrupción, de prevención y protección de personas en situación de violencia y vulnerabilidad y de modernización de la gestión del Estado [...] el Poder Ejecutivo está facultado para legislar en materia de prevención y protección de las personas en situación de violencia y vulnerabilidad a fin de establecer medidas para promover la inclusión de las personas con discapacidad, garantizar el derecho al ejercicio de su capacidad jurídica en condiciones de igualdad [cursivas añadidas]" (Sustento del Decreto Legislativo 1384). 
Se orienta a integrar al sujeto con discapacidad a la sociedad, permitiéndole interactuar en su mundo de relación de manera libre y plena, sin restricciones, obstáculos ni trabas. Las barreras se eliminan en pro de la equiparación de oportunidades. A través de este nuevo sistema se reconoce la autodeterminación y dignidad de las personas con discapacidad. De ese modo, la regla es que todas las personas con discapacidad tienen plena capacidad en igualdad de condiciones con los demás en todos y cada uno de los aspectos de la vida.

Reconocer el derecho a la capacidad a todos y para todos implica facilitar las medidas de apoyo y salvaguardias que permitan y promuevan el ejercicio de los derechos. La nueva regulación de las personas con discapacidad es extensa e importante. Y, como hemos dicho, nace de la teoría de los derechos humanos, no del propio sistema civil. A decir de Bariffi (2020a):

[...] el derecho civil clásico se ha mantenido al margen del discurso ético y jurídico en torno a los derechos humanos. Y lo que resulta curioso de este fenómeno es que el derecho civil aborda o regula cuestiones fundamentales de derechos humanos. (p. 3)

La reforma del Código Civil no solo ha significado la modificación de disposiciones en los libros "Derechos de las personas", “Acto jurídico", "Derecho de familia”, “Derecho de sucesiones", “Derechos reales”, “Las obligaciones" y "Fuente de las obligaciones”, sino que, además, ha obligado al operador jurídico a reconceptualizar algunas instituciones del ordenamiento y a conocer otras nuevas.

Se incorpora un nuevo capítulo, el capítulo cuarto "Apoyos y salvaguardias", dentro del título II "Instituciones supletorias de amparo", de la sección cuarta "Amparo familiar" del libro III “Derecho de familia” del Código Civil (véase la tabla 3).

\section{Tabla 3}

Ubicación del capítulo cuarto "Apoyos y salvaguardias" en el Código Civil

\begin{tabular}{|c|c|c|}
\hline \multicolumn{3}{|c|}{ Código Civil } \\
\hline \multirow{3}{*}{ Amparo familiar } & \multirow{3}{*}{ Instituciones supletorias de amparo } & Tutela \\
\hline & & Curatela \\
\hline & & Apoyos y salvaguardias \\
\hline
\end{tabular}

Elaboración propia

\section{Contenido de la reforma}

Los cambios realizados en cada libro tuvieron un gran impacto por el nuevo contenido de los artículos. Por esta razón, se realizará un breve resumen del contenido de estos (véase la tabla 4). 
Tabla 4

Resumen de los cambios en los libros II, II, III, IV y V del Código Civil

\begin{tabular}{|c|c|}
\hline Libro I & Resumen del nuevo contenido \\
\hline Personas & $\begin{array}{l}\text { - Se reconoció que las personas con discapacidad tenían derecho a la capacidad jurídica, } \\
\text { a la plena capacidad de ejercicio en igualdad de condiciones. } \\
\text { - El único supuesto de incapacidad absoluta se reduce a los menores de } 16 \text { años, salvo } \\
\text { para aquellos actos determinados por ley. } \\
\text { - Se establece que serán las propias personas con discapacidad las que manifestarán } \\
\text { su voluntad de contar con apoyos y salvaguardias (designados judicial o } \\
\text { notarialmente); en el caso de que no sea posible que estas emitan su voluntad, estos le } \\
\text { serán designados judicialmente. } \\
\text { - Los representantes legales ya no ejercerán los derechos legales de las personas con } \\
\text { discapacidad, en tanto ya no se considera que estas no son susceptibles de ejercer su } \\
\text { capacidad jurídica. }\end{array}$ \\
\hline Libro II & Resumen del nuevo contenido \\
\hline Acto jurídico & $\begin{array}{l}\text { - En cuanto a los requisitos de configuración del acto jurídico, el requisito "agente capaz" } \\
\text { es reemplazado por el término "plena capacidad de ejercicio, salvo las restricciones } \\
\text { contempladas en la ley". Ello debido a que la terminología que hacía referencia a las } \\
\text { personas con discapacidad como "incapaces" fue corregida a través de la reforma. } \\
\text { - Se incluye el lenguaje de señas, los medios alternativos de comunicación, los ajustes } \\
\text { razonables o los apoyos requeridos por una persona con discapacidad como medios } \\
\text { para la manifestación de voluntad. } \\
\text { - Se derogó la segunda causal de nulidad, debido a que esta hacía referencia a que un } \\
\text { acto jurídico sería nulo si era practicado por una persona absolutamente incapaz. } \\
\text { Nuevamente cabe mencionar que, gracias a la reforma, finalmente se reconoció plena } \\
\text { capacidad jurídica a las personas con discapacidad, quienes anteriormente no podían } \\
\text { realizar a título propio un acto jurídico sin caer en una causal de nulidad. } \\
\text { - Por esta misma razón, se derogó el precepto que incidía en considerar "la incapacidad } \\
\text { relativa del agente" como causal de anulabilidad del acto jurídico. }\end{array}$ \\
\hline Libro III & Resumen del contenido \\
\hline Familia & $\begin{array}{l}\text { - Fueron derogados los numerales que establecían que las personas con "enfermedades } \\
\text { crónicas, contagiosas, transmisibles por herencia o de vicio, así como las que padezcan } \\
\text { de enfermedad mental crónica" se encontraban impedidas de contraer matrimonio. } \\
\text { - Siguiendo esta línea, también fueron derogados los mismos supuestos mencionados } \\
\text { en el anterior punto como causales de nulidad de matrimonio. } \\
\text { - Se establece que los hijos extramatrimoniales de los menores de } 14 \text { años podrán ser } \\
\text { reconocidos a través de apoyos designados judicialmente (anteriormente este hecho } \\
\text { no era posible hasta que el adolescente cumpla los } 14 \text { años de edad). } \\
\text { - Ya no se considera que el hecho de que una persona se encuentre interdictada sea una } \\
\text { causal de suspensión de patria potestad; esta se suspenderá exclusivamente cuando } \\
\text { la persona se encuentre en estado de coma, siempre que no hubiera designado un } \\
\text { apoyo con anterioridad. } \\
\text { - Las personas con retraso mental o que presentan deterioro mental ya no se } \\
\text { encuentran sujetas a la curatela. }\end{array}$ \\
\hline
\end{tabular}




\begin{tabular}{|c|c|}
\hline & $\begin{array}{l}\text { - La interdicción podrá ser solicitada por el cónyuge, parientes o el Ministerio Público } \\
\text { habituales y los toxicómanos. Las personas con discapacidad no se encuentran sujetas } \\
\text { a este régimen. } \\
\text { - La curatela para los supuestos mencionados en líneas anteriores deberá ser } \\
\text { designada por un juez. } \\
\text { - Se implementa una nueva regulación de los apoyos y salvaguardias, se establece que } \\
\text { cualquier persona mayor de edad puede acceder libremente a estos si considera que } \\
\text { ello sería beneficioso para su capacidad de ejercicio. } \\
\text { - La persona que solicita los apoyos es la que determinará su forma, identidad, alcance, } \\
\text { duración, etcétera. Los apoyos no poseen facultad de representación de manera } \\
\text { inherente. } \\
\text { - Se establece que las salvaguardias son medidas que buscan garantizar el respeto de } \\
\text { los derechos, la voluntad y las preferencias de la persona que recibe los apoyos. Busca } \\
\text { prevenir el abuso y evitar poner en riesgo los derechos de las personas asistidas. }\end{array}$ \\
\hline Libro IV & Resumen del contenido \\
\hline Sucesiones & $\begin{array}{l}\text { - Gracias a la reforma, las personas con discapacidad sí pueden otorgar un testamento } \\
\text { válido. } \\
\text { - Se incluye el otorgamiento de ajustes razonables o apoyos para la manifestación } \\
\text { de la voluntad en el caso de las personas con discapacidad que deseen realizar un } \\
\text { testamento. } \\
\text { - Ya no se exige a las personas con discapacidad visual o auditiva tener que leer por sí } \\
\text { mismos el testamento. Además, si no es posible que la persona realice una firma, se } \\
\text { firmará el testamento a través de huella dactilar. } \\
\text { - Se deroga el numeral en el que se establecía que el testamento emitido por una } \\
\text { persona con discapacidad de cualquier tipo era causal de nulidad de este. }\end{array}$ \\
\hline Libro V & Resumen del contenido \\
\hline Reales & $\begin{array}{l}\text { - Se determina que, si uno de los copropietarios es una persona contemplada en los } \\
\text { supuestos de incapacidad absoluta o relativa, la partición convencional se someterá a } \\
\text { aprobación judicial. El cambio en este artículo recae en el término anteriormente mal } \\
\text { empleado ("incapaz"). }\end{array}$ \\
\hline Libro VI & Resumen del contenido \\
\hline Obligaciones & $\begin{array}{l}\text { - Cuando el crédito fuese litigioso o lo reclamaran varios acreedores, se establece que el } \\
\text { pago por consignación deberá ser judicial o extrajudicial cuando el acreedor fuese una } \\
\text { persona menor de edad que no recaiga en ningún supuesto especial, pródigo, ebrio } \\
\text { habitual, toxicómano, se encuentre en estado de coma, quien incurre en mala gestión } \\
\text { y los que sufren pena que lleva anexa la interdicción civil, siempre que no tuviesen } \\
\text { representante, curador o apoyo designado. }\end{array}$ \\
\hline
\end{tabular}


(continuación)

\begin{tabular}{ll}
\hline Libro VII & Resumen del contenido \\
\hline Contratos & - Se reconoce que las personas con capacidad de ejercicio restringido pueden celebrar \\
& contratos relacionados con las necesidades ordinarias de su vida diaria. \\
& - Se establece que la persona que cuenta con apoyos es responsable por sus propias \\
& decisiones, incluso de aquellas realizadas en conjunto con aquel, teniendo derecho \\
& a repetir contra este. Salvo el caso de las personas que se encuentren en estado de \\
& coma. Anteriormente, se consideraba que las personas con discapacidad que contaban \\
& con apoyos no eran responsables por las acciones realizadas en su representación. \\
\hline Libro VIII & Resumen del contenido \\
\hline Prescripción y & - Será causal de suspensión de la prescripción cuando las personas con capacidad de \\
caducidad & ejercicio restringido no cuenten con sus representantes legales. \\
& - Asimismo, se suspende la prescripción para las personas en estado de coma y las \\
& personas que brindan apoyos necesarios a estas (durante el tiempo que les presten \\
& apoyo). \\
\hline Libro IX & Resumen del contenido \\
\hline Pegistros & - Se detalla que son susceptibles de registro las resoluciones o escrituras públicas en \\
& las que se establezca o se modifique la designación de apoyos y salvaguardias de \\
& personas naturales en el Registro Personal. Anteriormente el texto indicaba que en su \\
& lugar serían inscritas las resoluciones que declaren la incapacidad y las que limiten la \\
& capacidad de las personas. \\
& o al apoyo y las que las dejen sin efecto. En el texto anterior se indicaba que solo era \\
& posible registrar el nombramiento de tutor o curador \\
\hline & \\
\hline
\end{tabular}

Elaboración propia

Impacto de la reforma del Código Civil en cifras

El Decreto Legislativo 1384 ha modificado el Código Civil en casi la totalidad de sus libros, salvo uno. Los cambios se presentan en las tablas $5,6,7$ y 8 .

Tabla 5

Impacto de las modificaciones de los libros del Código Civil

\begin{tabular}{llcccc}
\hline & Libros & \multicolumn{3}{c}{ Artículos } & $\begin{array}{c}\text { Impacto } \\
\text { total }\end{array}$ \\
\cline { 3 - 5 } & & Modificados & Derogados & Incorporados & 7 \\
\hline Libro I & Personas & 5 & 0 & 2 & 7 \\
Libro II & Acto jurídico & 5 & 2 & 0 & 34 \\
Libro III & Familia & 15 & 11 & 0 & 4 \\
Libro IV & Sucesiones & 4 & 0 & 0 & 1 \\
Libro V & Reales & 1 & 0 & & (continúa)
\end{tabular}


(continuación)

\begin{tabular}{|c|c|c|c|c|c|}
\hline Libro VI & Obligaciones & 1 & 0 & 0 & 1 \\
\hline Libro VII & Contratos & 1 & 2 & 1 & 4 \\
\hline Libro VIII & $\begin{array}{l}\text { Prescripción y } \\
\text { caducidad }\end{array}$ & 1 & 0 & 0 & 1 \\
\hline Libro IX & Registros Públicos & 1 & 0 & 0 & 1 \\
\hline Libro X & $\begin{array}{l}\text { Internacional } \\
\text { privado }\end{array}$ & 0 & 0 & 0 & 0 \\
\hline \multicolumn{2}{|c|}{ Impacto total } & 34 & 15 & 11 & 60 \\
\hline
\end{tabular}

Elaboración propia

Tabla 6

Artículos modificados en cada libro del Código Civil

\begin{tabular}{lllc}
\hline & \multicolumn{1}{c}{ Libros } & \multicolumn{1}{c}{ Artículos modificados } & Impacto total \\
\hline Libro I & Personas & Art. 3, art. 42, art. 43, art. 44, & 5 \\
Libro II & Acto jurídico & Art. 140, art. 141, art. 219, art. & 5 \\
& & 221, art. 226 & \\
Libro III & Familia & Art. 241, art. 243, art. 274, art. & 15 \\
& & 389, art. 466, art. 564, art. 565, \\
& & art. 566, art. 583, art. 585, art. & \\
& & 589, art. 599, art. 606, art. 610, & \\
Libro IV & Sucesiones & art. 613 & 4 \\
& & Art. 687, art. 696, art. 697, art. & \\
Libro V & Reales & 808 & 1 \\
Libro VI & Obligaciones & Art. 987 & 1 \\
Libro VII & Contratos & Art. 1252 & 1 \\
Libro VIII & Prescripción y caducidad & Art. 1994 & 1 \\
Libro IX & Registros Públicos & Art. 2030 & 1 \\
Libro X & Internacional privado & Ningún artículo & 1 \\
\hline
\end{tabular}

Elaboración propia 
Tabla 7

Artículos derogados en cada libro del Código Civil

\begin{tabular}{lllc}
\hline & \multicolumn{1}{c}{ Libros } & \multicolumn{1}{c}{ Artículos derogados } & Impacto total \\
\hline Libro I & Personas & Ningún artículo & 0 \\
Libro II & Acto jurídico & Art. 228, art. 229 & 2 \\
Libro III & Familia & Art. 569, art. 570, art. 571, art. & 11 \\
& & 572, art. 578, art. 580, art. 581, & \\
& & art. 582, art. 592, art. 612, art. 614 & \\
Libro IV & Sucesiones & Ningún artículo & 0 \\
Libro V & Reales & Ningún artículo & 0 \\
Libro VI & Obligaciones & Ningún artículo & 0 \\
Libro VII & Contratos & Art. 1975, art. 1976 & 2 \\
Libro VIII & Prescripción y caducidad & Ningún artículo & 0 \\
Libro IX & Registros Públicos & Ningún artículo & 0 \\
Libro X & Internacional privado & Ningún artículo & 0 \\
\hline
\end{tabular}

Elaboración propia

Tabla 8

Artículos incorporados en cada libro del Código Civil

\begin{tabular}{lllc}
\hline & \multicolumn{1}{c}{ Libros } & \multicolumn{1}{c}{ Artículos incorporados } & Impacto total \\
\hline Libro I & Personas & Art. 45-A, art. 45-B & 2 \\
Libro II & Acto jurídico & Ningún artículo & 0 \\
Libro III & Familia & Art. 659-A, art. 659-B, art. & 8 \\
& & 659-C, art. 659-D, art. 659- & \\
& & E, art. 659-F, art. 659-G, art. & \\
Libro IV & Sucesiones & Ningún artículo & 0 \\
Libro V & Reales & Ningún artículo & 0 \\
Libro VI & Obligaciones & Ningún artículo & 0 \\
Libro VII & Contratos & Art. 1976-A & 1 \\
Libro VIII & Prescripción y caducidad & Ningún artículo & 0 \\
Libro IX & Registros Públicos & Ningún artículo & 0 \\
Libro X & Internacional privado & Ningún artículo & 0 \\
\hline
\end{tabular}

Elaboración propia

Entre modificaciones, derogaciones e incorporaciones, tenemos un impacto que se ve reflejado en nueve de los diez libros del Código Civil, teniendo como resultado un total de sesenta artículos. Representa la más grande modificación que ha tenido el Código por 
una sola norma a lo largo de su historia. Esta modificación representa cerca del 2,8 \% del total, si tenemos en cuenta que hoy el Código Civil tiene 2142 artículos.

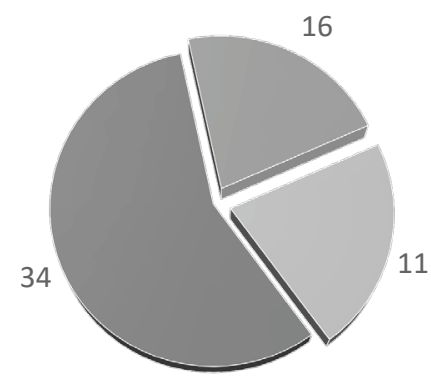

$$
\begin{aligned}
& \text { - Artículos modificados } \square \text { Artículos derogados } \\
& \text { - Artículos incorporados }
\end{aligned}
$$

Figura 1. Impacto total del Decreto Legislativo 1384 en el Código Civil

Nota. Son 34 artículos modificados, 15 derogados y 11 incorporados.

Elaboración propia

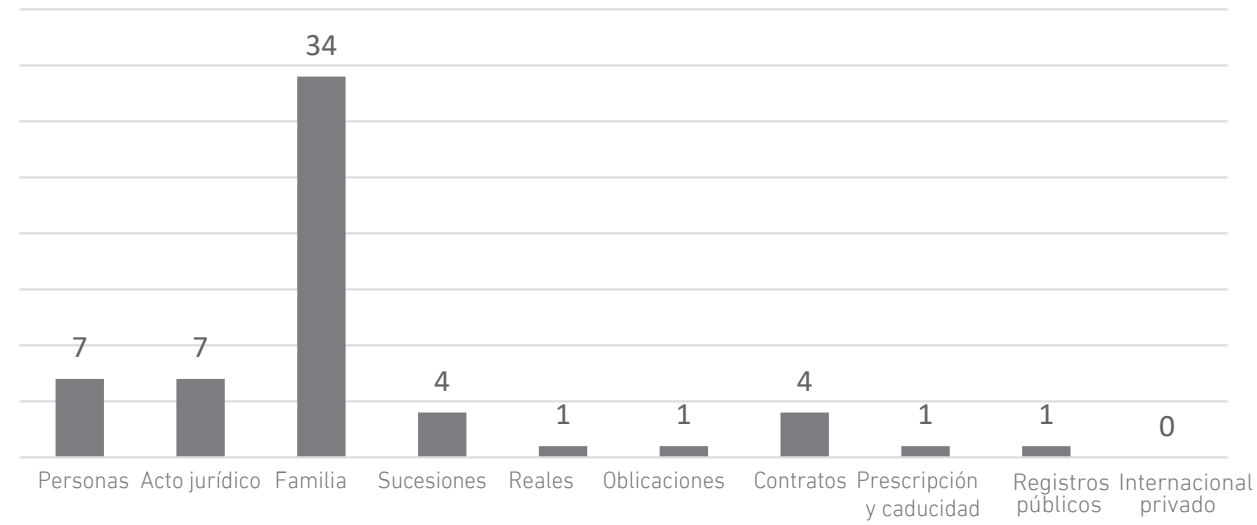

Figura 2. Impacto del Decreto Legislativo 1384 en cada libro del Código Civil

Nota. De los 34 artículos modificados, 15 corresponden al libro "Derecho de familia", el cual ha concentrado mayor atención en materia de modificaciones.

Elaboración propia 


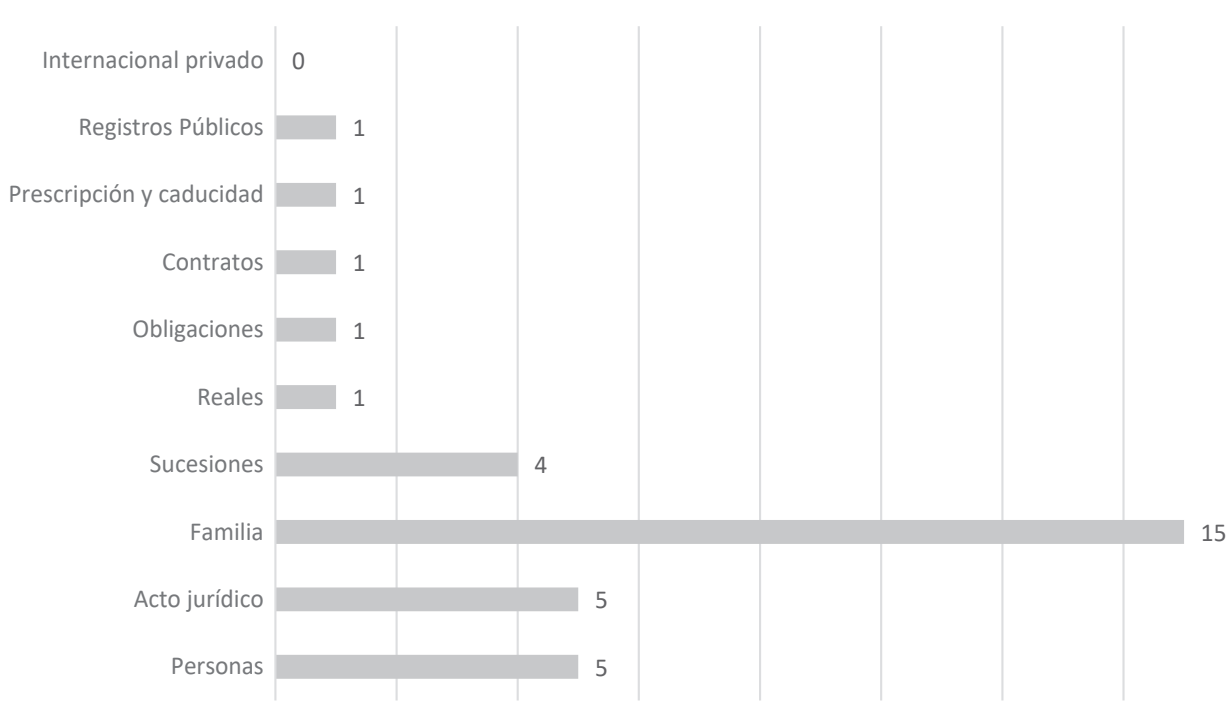

Figura 3. Artículos modificados por el Decreto Legislativo 1384 en cada libro del Código Civil Elaboración propia

Esta es una importante reforma que no pasa desapercibida: es la más grande que ha tenido el Código por una sola norma. Además, no solo es una reforma de ajuste normativo, sino que reconceptualiza una institución vertebral del derecho privado como es la capacidad. Marca un nuevo concepto en materia de discapacidad; asimismo, no es una modificación acabada: todavía queda pendiente llevarla a la práctica, ejecutarla y ponerla en marcha.

Este nuevo régimen, a decir de Santillán Santa Cruz (2020), establece:

[El] conjunto de reglas dirigidas a ordenar jurídicamente el acceso libre y voluntario de toda persona mayor de edad a los apoyos y salvaguardias que coadyuven al ejercicio de su capacidad de obrar, en ajustamiento a las previsiones que contempla el sistema para la determinación, designación, actuación y duración del apoyo, así como a las que se refieran a la determinación de las medidas de salvaguardia destinadas a asegurar que la persona designada como apoyo actúe conforme al mandato encomendado. (p. 564)

Grosso modo, la reforma se puede esquematizar como se precia en la tabla 9. 
Tabla 9

Resumen de la reforma del Código Civil por el Decreto Legislativo 1384

La capacidad jurídica como derecho de toda persona

- Toda persona (capaz o discapaz) tiene capacidad jurídica, esta incluye:

- Capacidad de goce

- Capacidad plena de ejercicio

- Los mayores de 14 años casados o que sean padres

- Puede ser restringida por ley

- Incapacidad absoluta

- Solo por minoridad

- Capacidad de ejercicio restringida

- Reconoce la discapacidad percibida

- Únicas causas de interdicción y curatela

- Incorpora como causa el estado de coma

- Elimina el retardo y el deterioro mental como causales

- Derecho a solicitar o designar ajustes razonables y apoyos

- Reconoce el modelo de social asistencia a través del apoyo en la toma de decisiones

- Reafirma la autonomía jurídica de las personas con discapacidad a través de apoyos y salvaguardias

- Los apoyos son sujetos que coadyuvan en el ejercicio de la capacidad jurídica

- No tienen representación, salvo delegación expresa o sea obligatorio

- Pueden ser solicitados notarial o judicialmente (ante la falta de voluntad, solo procede judicialmente)

- Las salvaguardias son medidas que impiden el abuso de la función y la influencia indebida del apoyo

- La persona con discapacidad es responsable de sus decisiones

Elaboración propia

Ajustes realizados a partir de las Observaciones Finales del Comité sobre los Derechos de las Personas con Discapacidad

A la luz de las Observaciones Finales del Comité sobre los Derechos de las Personas con Discapacidad ( 16 de mayo del 2012) ${ }^{7}$ realizadas al Perú, a la fecha se ha producido un interesante movimiento de ajuste, tanto normativo como jurisprudencial (véase la tabla 10).

7 Examen de los informes presentados por los Estados partes en virtud del artículo 35 de la Convención. Observaciones Finales del Comité sobre los Derechos de las Personas con Discapacidad. Perú. CRPD/C/PER/CO/1, del 16 de mayo del 2012. 
Tabla 10

Análisis de los cambios a la luz de las Observaciones Finales del Comité sobre los Derechos Humanos de las Personas con Discapacidad (2012)

\begin{tabular}{|c|c|c|}
\hline Observaciones Finales & $\begin{array}{c}\text { A la fecha, se observan los } \\
\text { siguientes avances }\end{array}$ & No se han presentado avances \\
\hline $\begin{array}{l}\text { Aprobación de la Ley } 29392 \\
\text { de infracciones y sanciones } \\
\text { por el incumplimiento de la } \\
\text { Ley General de la Persona con } \\
\text { Discapacidad } \\
\text { Ley General de la Persona con } \\
\text { Discapacidad } \\
\text { Aprobación del Plan de lgualdad } \\
\text { de Oportunidades para las } \\
\text { Personas con Discapacidad } \\
2009-2018 \quad \text { integración } \\
\text { Aprobación de un programa } \\
\text { piloto sobre las con } \\
\text { psicosocial de las personas con } \\
\text { discapacidad en la región de } \\
\text { Tumbes los } \\
\text { El Proyecto de Ley sobre los } \\
\text { Derechos de las Personas con } \\
\text { Discapacidad presentado al } \\
\text { Congreso en marzo del } 2011 \\
\text { Aprobación de la Ley } 29535 \\
\text { sobre el lenguaje de señas } \\
\text { Aumento del gasto en } \\
\text { programas para personas con } \\
\text { discapacidad }\end{array}$ & 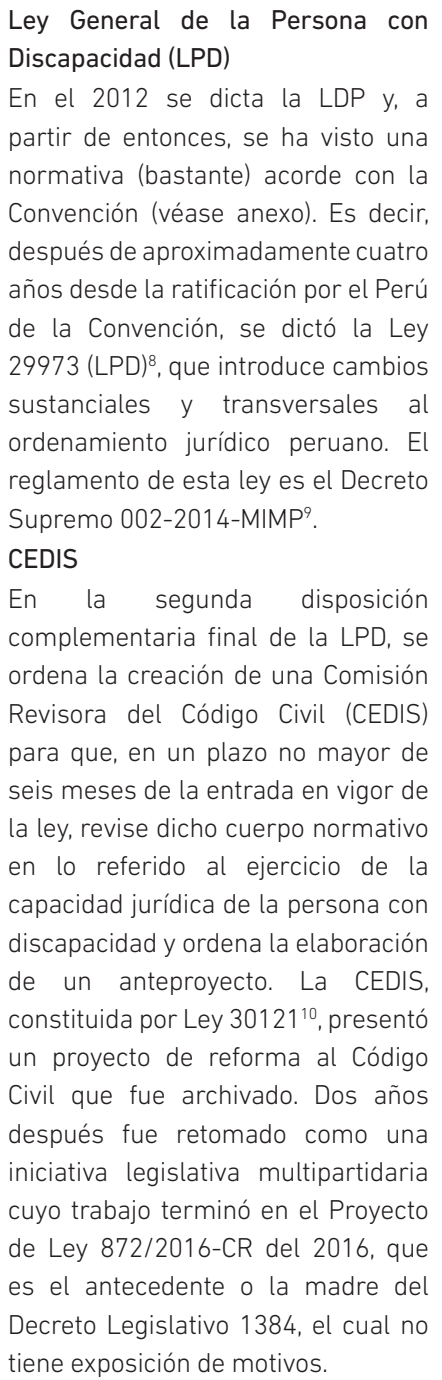 & $\begin{array}{l}\text { No hay ajuste pleno de la } \\
\text { normativa a la Convención; } \\
\text { solo se han modificado algunas } \\
\text { normas, pero han quedado otras } \\
\text { que no se entienden derogadas } \\
\text { tácitamente. } \\
\text { Queda aún en la LPD una } \\
\text { definición de discapacidad que } \\
\text { se aferra al criterio médico } \\
\text { rehabilitador, tendiendo tímida- } \\
\text { mente a incorporar un criterio } \\
\text { social al hablar de las barreras } \\
\text { actitudinales. } \\
\text { No hay un avance en el } \\
\text { tratamiento y respeto del } \\
\text { derecho a la igualdad y no } \\
\text { discriminación de las personas } \\
\text { con discapacidad pertenecientes } \\
\text { a grupos indígenas y de } \\
\text { minorías; estas corren un } \\
\text { alto riesgo de sufrir múltiples } \\
\text { discriminaciones. } \\
\text { Hay que trabajar más en la } \\
\text { accesibilidad de las personas } \\
\text { con discapacidad. } \\
\text { No se ha derogado plenamente } \\
\text { la interdicción; se ha revisado } \\
\text { la tutela y la curatela, pero no } \\
\text { hay una sintonía cabal con la } \\
\text { Convención (artículo 12). La } \\
\text { Constitución (artículo } 7 \text { ) nos } \\
\text { sigue hablando de la persona } \\
\text { incapacitada y con deficiencia } \\
\text { mental. }\end{array}$ \\
\hline
\end{tabular}

8 Publicada en el diario oficial El Peruano el 24 de diciembre del 2012.

9 Publicado en el diario oficial El Peruano el 7 de abril del 2014.

10 Publicada en el diario oficial El Peruano el 5 de diciembre del 2013. 
(continuación)

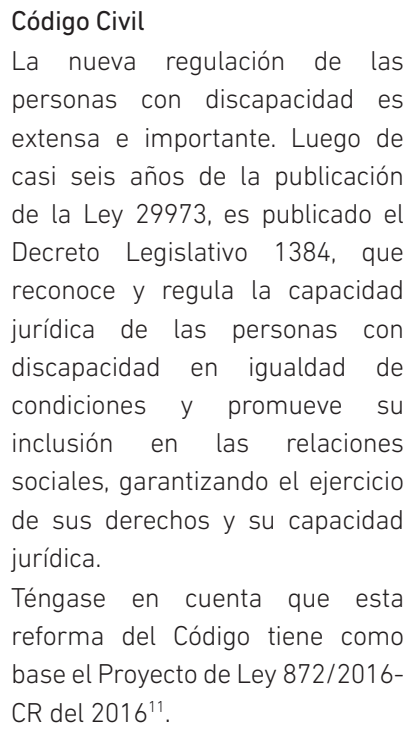

Elaboración propia

\section{La reforma en el campo doctrinario: comentarios y posturas}

Al analizar las modificaciones, derogaciones y adiciones que han conllevado estos cambios en nuestro Código, es posible afirmar que esta no fue una reforma integral, como algunos sostienen, entre ellos Mejía Rosasco (2019, p. 52). Se trata de una reforma casi integral. Se mitigó la teoría de las incapacidades; sin embargo, no fue abolida por completo. Se intentó hacer una reforma total, pero ello no se logró, pues se mantiene la incapacidad absoluta, la interdicción y curatela para ciertos casos.

Esto ha sido advertido por la Defensoría del Pueblo, que incluso ha manifestado que "aún quedan pendientes otros aspectos de nuestra legislación sobre la discapacidad. Por ejemplo, la reforma no incluyó a las denominadas PCD [personas con discapacidad] percibidas: el Código Civil peruano aún contempla a los 'ebrios habituales' y 'toxicómanos' como personas con incapacidad restringida" (Mamani, 2018, párr. 5). Cabe mencionar que estos últimos no son discapaces, como bien indica Mejía Rosasco (2019), ya que "la situación en la que se encuentran no es ninguna de las previstas en la Convención" (p. 64).

11 Publicada en el diario oficial El Peruano el 5 de diciembre del 2013. 
La Convención detalla los supuestos en los que se considera que una persona posee una discapacidad en su artículo 1:

Las personas con discapacidad incluyen a aquellas que tengan deficiencias físicas, mentales, intelectuales o sensoriales a largo plazo que, al interactuar con diversas barreras, puedan impedir su participación plena y efectiva en la sociedad, en igualdad de condiciones con las demás.

No es posible incluir a los toxicómanos ni a los ebrios habituales dentro de esta categoría según la propia descripción de las personas con discapacidad, establecida en la Convención. En este aspecto, es posible presumir que estos supuestos no se basaron estrictamente en la Comisión.

Como era de esperarse, el nuevo tratamiento de la capacidad tiene seguidores y detractores, quienes están a favor y en contra de la reforma. De alguna manera, la tabla 11 presenta cómo se dividen estas posiciones (aunque no pretendemos que este sea un esquema acabado o rígido).

Tabla 11

Clasificación de las posturas a favor y en contra del nuevo tratamiento de la capacidad

\begin{tabular}{ll}
\hline A favor & En contra \\
\hline $\begin{array}{l}\text { Lescano Feria (2018), Balarezo Reyes } \\
\text { (2018), Mejía Rosasco (2019), Wong }\end{array}$ & $\begin{array}{l}\text { (2018, 2019), Ortega López (2018), Castillo Freyre y Chipana } \\
\text { Abad (2019) }\end{array}$ \\
& $\begin{array}{l}\text { Catalán (2018), Cárdenas Krenz y Della Rosa Leciñana (2018), } \\
\text { Villanueva (2018), Campos García (2018) }\end{array}$ \\
\hline \multicolumn{1}{c}{ Intermedia } \\
\hline Cieza Mora y Olavarría Parra (2018), Plácido Vilcachagua (2019), \\
Tantaleán Odar (2018), Agurto Gonzáles y Díaz Díaz (2018), \\
Santillán y Bardales (comunicación personal, 20 de agosto del 2020) \\
\hline
\end{tabular}

Elaboración propia

La divergencia es clara, no hay uniformidad de posiciones, autores utroque trahunt. Más allá de ello, el Código fue modificado y tenemos un nuevo sistema en la línea de lo social, integrador e igualitario; queda respetarlo y sobre todo implementarlo.

\section{REFLEXIONES FINALES}

El concepto de capacidad evolucionó totalmente gracias a la Convención. El reconocimiento de capacidad jurídica plena a las personas con discapacidad, así como el reemplazo de la interdicción y curatela por el sistema de apoyos y salvaguardias, sin 
duda significaron un gran avance para el derecho civil, que siguió la premisa de regular en su normativa estos principios de derecho internacional.

La aceptación del modelo social, la nueva definición establecida en esta, así como los criterios de su tratamiento jurídico, dieron puerta abierta a una mayor inclusión dentro de esta categoría. Podemos comprobar ello al comparar el Censo Nacional del año 1993, en el que se registró únicamente al 1,3 \% de la población como personas con discapacidad, con el Censo Nacional del año 2007, que registró que en el 10,9 \% de los hogares de nuestro país existe por lo menos una persona con discapacidad (CONADIS, 2018, p. 36). Aquel crecimiento exponencial en las cifras se debe únicamente a este nuevo entendimiento, más amplio e inclusivo, de lo que significa ser una persona con discapacidad (CONADIS, 2018, p. 31).

Según los Censos Nacionales 2017, XII de Población y VII de Vivienda, se registraron 3209261 personas con discapacidad en todo el Perú. Teniendo en cuenta que, en esta misma data, se contó un total de 31237385 habitantes en nuestro país, esta cantidad de personas representa el $10,3 \%$ del total de peruanos. Asimismo, se señala que solo el $9,9 \%$ de ellos se encuentran inscritos en el Registro Nacional de la Persona con Discapacidad (INEI, 2017).

En este contexto, resulta de difícil comprensión cómo y por qué adaptar la normativa de nuestro Código Civil a los derechos fundamentales de 3209261 peruanos demoró diez años. Ello teniendo en cuenta que los tratados internacionales en los que se encuentra adscrito nuestro país tienen rango constitucional, es decir que nuestra normativa civil contradecía un mandato de mayor jerarquía. A modo de reflexión, es necesario recordar cuál es la función principal del derecho civil y por qué es tan importante la rápida adaptación de nuestro Código Civil al cambio social y a los derechos fundamentales.

El derecho civil regula las relaciones jurídicas entre los sujetos privados; en este sentido, como sostiene Vidal Ramírez (2014), "el derecho civil responde a la necesidad humana de vivir en paz, contribuyendo al trazo de una sociedad en la que los individuos, como personas, puedan realizarse y entablar sus relaciones jurídicas con tranquilidad y paz" (p. 20). En este ámbito, la aplicación efectiva de normas constitucionales que recaen en la relación entre privados es de suma importancia, especialmente para poblaciones históricamente discriminadas, como lo fueron las personas con discapacidad.

Esta diferencia de diez años entre la Convención y la reforma del Código nos deja como lección la importancia de tener un sistema que se adapte con mayor rapidez a los cambios, especialmente si versan sobre derechos humanos. Durante todo aquel tiempo, las personas con discapacidad de nuestro país no pudieron acceder a múltiples derechos reconocidos recientemente por la reforma. Actos jurídicos del día a día, como llevar a cabo contratos simples, realizar un testamento, contraer matrimonio, 
tener patria potestad sobre sus descendientes, etcétera, no les eran permitidos. En retrospectiva, muchas de las limitaciones impuestas antes de la reforma significaban verdaderamente una exclusión sistemática de las personas con discapacidad, que limitaba (incluso en su totalidad en algunos casos) la autonomía de su voluntad, facultad básica del derecho civil.

La reforma de la capacidad en el Código Civil peruano trasciende de representar simples modificaciones de artículos y de dar nuevos tratamientos a las instituciones preexistentes. Tras un largo proceso, esta reforma ciertamente mejoró el tratamiento de la capacidad, brindando una normativa más beneficiosa que la anterior, dado que la finalidad de un adecuado tratamiento de la capacidad en materia civil es que verdaderamente este facilite el día a día de millones de peruanos y los reconozca en igualdad de derechos. La realidad es que, más allá de la discusión doctrinaria acerca de si el nuevo sistema de regulación de la capacidad es el correcto o el mejor, lo más importante es que este sea implementado, aplicado y que las personas con discapacidad conozcan sus derechos y las nuevas modificaciones.

\section{REFERENCIAS}

Agurto Gonzáles, C. A., y Díaz Díaz, M.-P. G. (2018). Capacidad jurídica: el histórico problema de una categoría fundamental en el derecho. A propósito del Decreto Legislativo N. ${ }^{\circ}$ 1384. Gaceta Civil \& Procesal Civil, 65, 137-164.

Balarezo Reyes, E. (2018). La nueva redimensión de la capacidad jurídica con motivo del Decreto Legistivo N. ${ }^{\circ} 1384$. Actualidad Civil, 52, 83-99.

Bariffi, F. (2020a). El derecho a decidir de las personas con discapacidad: dignidad, igualdad y capacidad. En R. Constantino Caycho (Ed.), Diplomatura de estudio sobre reformas en capacidad jurídica de personas con discapacidad en América Latina 2020-01 (pp. 1-51). Pontificia Universidad Católica del Perú.

Bariffi, F. (2020b). El modelo de toma de decisiones con apoyos: de la teoría a la práctica. En A. Kraut (Ed.), Derechos y salud mental (vol. II, pp. 241-288). Rubinzal Culzoni.

Bermúdez Tapia, M. (2018). Legislando y desfigurando la naturaleza jurídica de la “capacidad jurídica” en el Perú. Gaceta Civil \& Procesal Civil, 65, 129-135.

Bregaglio, R., y Constantino, R. (2020). Un modelo para armar: la regulación de la capacidad jurídica de las personas con discapacidad en el Perú a partir del Decreto Legislativo 1384. Revista Latinoamericana en Discapacidad, Sociedad y Derechos Humanos, 4(1), 32-59.

Bustamante, S. (2019). Aplicando la reforma del Código Civil:capacidadjurídica y salvaguardias [Trabajo académico, Pontificia Universidad Católica del Perú]. https://tesis.pucp. 
edu.pe/repositorio/bitstream/handle/20.500.12404/16274/BUSTAMANTE_ ARCE_SHARON_GERALDINE\%20\%282\%29.pdf?sequence=5\&isAllowed=y

Campos García, H. (22 de enero del 2013). Discapacidad no es incapacidad. A veces no solo bastan las declaraciones de buenas intenciones. Jurídica. Suplemento de Análisis Legal de El Peruano, 440, 6-7.

Campos García, H. (2018). Apuntes sobre la capacidad jurídica y la validez de los negocios jurídicos en el Código Civil peruano. Actualidad Civil, 52, 65-81.

Cárdenas Krenz, R., y Della Rossa Leciñana, A. (2018). Comentarios a las recientes modificaciones del Código Civil en materia de capacidad. Gaceta Civil \& Procesal Civil, 65, 101-116.

Castillo Freyre, M., y Chipana Catalán, J. (2018). La pésima nueva regulación de la capacidad jurídica de las personas con discapacidad. Gaceta Civil \& Procesal Civil, $65,45-50$.

Cieza Mora, J., y Olavarría Parra, M. J. (2018). Errores y aciertos de la reciente legislación acerca de la discapacidad en el Perú. Nosotros, los normales. Gaceta Civil \& Procesal Civil, 64, 47-61.

Consejo Nacionalparala Integración delaPersonaconDiscapacidad.(2018).Aproximaciones sobre discapacidad en el Perú. Informe estadístico multisectorial. Edición del Autor. https://conadisperu.gob.pe/observatorio/wpcontent/uploads/2019/02/ Informe-Estadistico-Multisectorial.pdf

Corral Talciani, H. (2018). Curso de derecho civil. Parte general. Thomson Reuters.

Espinoza Espinoza, J. (2018). Las nuevas coordenadas impuestas en el Código Civil en materia de capacidad (o el problema de la "falta de discernimiento" en una reforma legislativa inconsulta y apresurada). Gaceta Civil \& Procesal Civil, 64, $13-25$.

Espinoza Espinoza, J. (2019). Derecho de las personas. Concebido y personas naturales

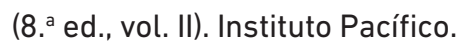

Farias, C. C., y Rosenvald, N. (2018). Curso de direito civil. Parte geral e LINDB (16. ${ }^{\text {a ed., }}$ vol. 1). JusPodivm.

Frecha, J. M. I. (2019). Capacidad jurídica y acceso a la justicia de las personas con discapacidad en Argentina. Revista Española de Discapacidad (REDIS), 7(2), 79-101.

Instituto Nacional de Estadística e Informática. (2017). Perfil sociodemográfico de la población con discapacidad. Edición del Autor. https://www.inei.gob.pe/media/ MenuRecursivo/publicaciones_digitales/Est/Lib1675/libro.pdf 
León Hilario, L. (2014). Parte subjetivamente compleja, indivisibilidad y anulabilidad por incapacidad relativa: la norma más oscura del Código Civil también cumple treinta años (¿y dice adiós?). Thémis, 66, 85-105.

León Hilario, L. (2019). Derecho privado. Parte general. Negocios, actos y hechos jurídicos. Pontificia Universidad Católica del Perú, Fondo Editorial.

Lescano Feria, P. (2108). La capacidad jurídica de las personas con discapacidad. A propósito del Decreto legislativo N.1 1384. Gaceta Civil \& Procesal Civil, 64, 83-92.

López, Á. B. (2015). Capacidad jurídica: una reflexión necesaria a la luz de la Convención sobre los Derechos de las Personas con Discapacidad. Anuario de Derechos Humanos, 11, 39-56.

Mamani, F. (14 de septiembre del 2018). Decreto Legislativo 1384: un importante paso para el ejercicio de la capacidad jurídica de las personas con discapacidad. Instituto de Democracia y Derechos Humanos de la PUCP. https://idehpucp.pucp.edu.pe/ notas-informativas/decreto-legislativo-no-1384-un-importante-paso-para-elejercicio-de-la-capacidad-juridica-de-las-personas-con-discapacidad/\#_ftn3

Mejía Rosasco, R. (2019). La implementación de la Convención de las Personas con Discapacidad en la función notarial. Colegio de Notarios del Perú, Fondo Editorial.

Orrego, J. (2019). Nuevo régimen de capacidad legal en colombia (Ley 1996 de 2019): la problemática de la presunción de capacidad y de la exigibilidad y cumplimiento de las obligaciones alimentarias derivadas de las relaciones de familia a las personas en situación de discapacidad. Revista Estudiantil de Derecho Privado, Universidad Externado de Colombia. https://red.uexternado. edu.co/nuevoregimen-de-capacidad-legal-en-colombia-ley-1996-de-2019la-problematica-de-la-presuncionde-capacidad-y-de-la-exigibilidad-ycumplimiento-de-las-obligaciones-alimentarias-derivadasde-las-rel

Ortega López, I. A. (2018). Los procesos de interdicción, designación del salvaguarda y autorización para disponer derechos de incapaces. Gaceta Civil \& Procesal Civil, 64, 93-104.

Palacios, A. (2015). Una introducción al modelo social de discapacidad y su reflejo en la Convención Internacional sobre los Derechos de las Personas con Discapacidad. En R. Bregaglio y E. Salmón (Eds.), Nueve conceptos claves para entender la Convención sobre los Derechos de las Personas con Discapacidad (pp. 9-33). Pontificia Universidad Católica del Perú, Fondo Editorial.

Palacios Martínez, E. (2018). Capacidad, declaración de voluntad y negocio jurídico: la “óptica” del Decreto Legislativo N. 1384. Gaceta Civil \& Procesal Civil, 65, 117-127. 
Plácido Vilcachagua, A. (2019). Discapacidad y capacidad jurídica. A propósito del Decreto Legislativo N.ํ 1384 que adecúa el Código Civil a la Convención sobre los Derechos de las Personas con Discapacidad. En M. Torres Carrasco (Ed.), Derecho procesal de familia (pp. 93-136). Gaceta Jurídica.

Quispe Villanueva, E. (2018). Análisis de las modificaciones efectuadas por el Decreto Legislativo N. ${ }^{\circ} 1384$ al Libro de los Derechos de las Personas del Código Civil. Gaceta Civil \& Procesal Civil, 65, 165-186.

Ramírez Niño de Guzmán, J. L. (2018). Autonomía, capacidad y validez de actos jurídicos de las personas con discapacidad. Gaceta Civil \& Procesal Civil, 64, 105-117.

Roca Mendoza, 0. (2015). La capacidad de las personas naturales: análisis del Código Civil a la luz de la Ley General de Discapacidad. Cambio de visión del derecho civil por los derechos humanos. Persona y Familia, 1(4), 113-137.

Rosso Nelson, R. A. R., De Sousa Rosso Nelson, I. C. A., y De Souza Costa, E. (2019). Da proteção jurídica das pessoas com deficiência no sistema jurídico brasileiro. Prolegómenos, 22(44), 97-116.

Santillán Santa Cruz, R. (2020). Acceso a apoyos y salvaguardias. En M. T. Muro Rojo (Ed.),

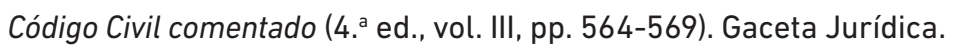

Simon Campaña, F. (2017). Introducción al estudio del derecho. Cevallos Editora Jurídica.

Sokolich Alva, M. I. (2015). Protección y defensa de la salud, el medio familiar y la comunidad. En W. Gutiérrez (Ed.), La Constitución comentada. Análisis artículo por artículo (3. ${ }^{a}$ ed., vol. I, pp. 569-574). Gaceta Jurídica.

Tantaleán Odar, R. M. (2018). El Decreto Legislativo 1384 y su influencia en algunos aspectos del derecho civil no patrimonial y procesal. Gaceta Civil \& Procesal Civil, 64, 63-82.

Tribunal Constitucional. Expediente 02480-2008-PA/TC; 11 de julio del 2008.

Tribunal Constitucional. Expediente 02313-HC/TC; 24 de septiembre del 2009.

Tribunal Constitucional. Expediente 02437-2013-PA/TC; 16 de abril del 2014.

Tribunal Constitucional. Expediente 01153-2013-PA/TC; 21 de agosto del 2014.

Tribunal Constitucional. Expediente 00194-2014-PHC/TC; del 30 de abril del 2019.

Torres Vásquez, A. (2018). La capacidad jurídica en el nuevo artículo 3 del Código Civil. Gaceta Civil \& Procesal Civil, 65, 51-100.

Varsi Rospigliosi, E. (22 de enero del 2013). Discapacidad y el Código Civil peruano. Retos para la nueva Comisión Revisora creada por Ley 29973. Jurídica. Suplemento de Análisis Legal de El Peruano, 440, 4-5. 
Varsi Rospigliosi, E., y Torres Maldonado, M. A. (2019). El nuevo tratamiento del régimen de la capacidad en el Código Civil peruano. Acta Bioethica, 25(2), 199-213. https:// actabioethica.uchile.cl/index.php/AB/article/view/54809/57879

Vega Mere, Y. (2014). La reforma del régimen legal de los sujetos débiles made by Mary Shelley: notas al margen de una novela que no pudo tener peor final. Gaceta Civil \& Procesal Civil, 64, 27-45.

Vidal Ramírez, F. (2014). La importancia del derecho civil y de su codificación en la sociedad. Entrevista a Fernando Vidal Ramírez. Thémis, 66, 19-24.

Vidal Ramírez, F. (2018). El Decreto Legislativo N. 1384 y el Código Civil. Gaceta Civil \& Procesal Civil, 65, 43-44.

Wong Abad, J. J. (2019). Del sistema de apoyo y salvaguardias conforme al Decreto Legislativo 1384. En M. Torres Carrasco (Ed.), Derecho procesal de familia (pp. 249-262). Gaceta Jurídica. 